\title{
Improving the biotechnology of growing Silurus Glanis L., Clarias Gariepinus, Pangasius Hypophthalmus catfish (Siluroidea) in the waters of energy facilities
}

\author{
Marina Kalaida ${ }^{1}$, Svetlana Borisova ${ }^{1, *}$, Evgeny Piganov $^{1},{\text { Farhad } \text { Ismagilov }^{1} \text {, and Andrey Kalaida }}^{2}$ \\ ${ }^{1}$ FSBEI HE "Kazan State Power Engineering University", Department of "Aquatic Bioresources and Aquaculture", Kazan, Russia \\ ${ }^{2}$ LLC "Biosphere - Fish"Kazan, Russia
}

\begin{abstract}
The modern biotechnologies of reproduction and cultivation of European catfish, African clary catfish and pangasius are considered. The development of biotechnology led to the development of a technology for its reproduction by the method of hormonal injection with preservation of life of the females and the euthanasia of the males for the collection of pure sperm. Further development of biotechnology is associated with the expansion of species diversity and the inclusion of African clary catfish and pangasius into aquaculture in warm waters.
\end{abstract}

\section{Introduction}

In the Middle Volga region, the historically main direction of work was pasture aquaculture on the basis of the largest reservoir in Europe - the Kuibyshev reservoir.

Before the regulation of the Volga River, P.A. Dryagin [1] does not indicate the common catfish (Silurus glanis L.) in the summary of commercial fish, but N.I. Kozhin [2] refers it not as an economically valuable fish species, but as a predatory fish "definitely subject to destruction". In accordance with such ideas about catfish as a rare object - a predator, when developing a working hypothesis for an integrated scheme for using the Volga in 1931 in the project for the construction of a hydroelectric power plant, catfish was not considered as a promising object for fishery and was included in the group of miscellaneous. Catfish was rare and was caught in single specimens in the Middle Volga (Fig. 2), where catches varied before flooding from 1.58 to 4.48 tons [3] (Fig. 1). After the formation of the Kuibyshev reservoir, the catfish catch did not exceed 20 tons, accounting for $0.2-0.6 \%$ in catches (Fig. 1).

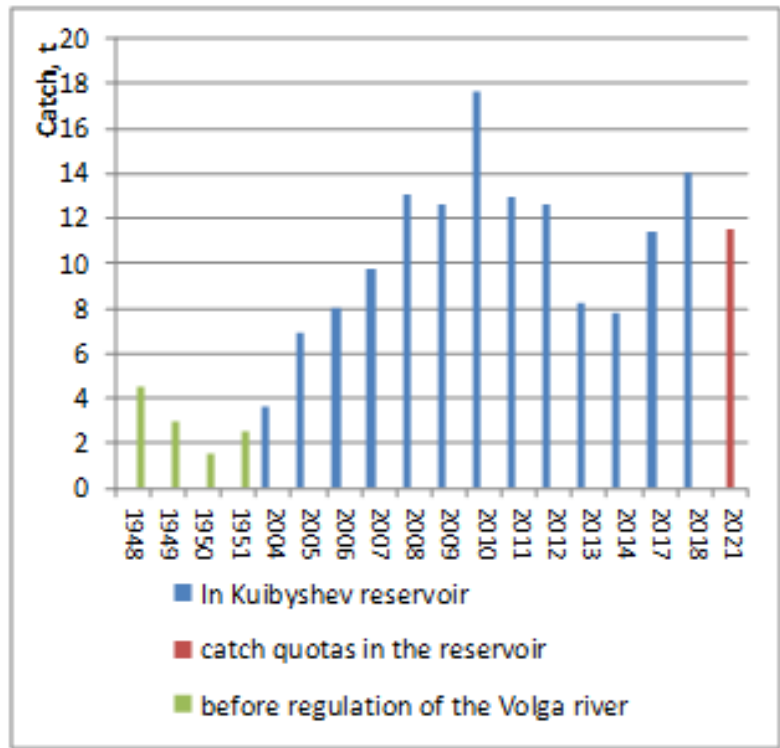

Fig. 1. Catfish catch from the Volga River in the flood zone of the Kuibyshev reservoir and in the reservoir.

In this regard, there are problems of improving the biotechnology of growing catfish in order to increase its production.

The purpose of our study is to consider the possibility of improving aquabiotechnology for growing catfish in the Middle Volga region based on the waters of energy facilities.

\section{Material and research technique}

In the course of the work, the analysis of the results of our own research and literature data on the ecology and

\footnotetext{
* Corresponding author: svetlana-zag@,bk.ru
} 
biology of commercially valuable catfish, statistical information on fish catches, biotechnologies of reproduction and cultivation of fish of different ages was carried out. When analyzing the population structure and biological characteristics of fish, traditional methods were used. Analyzed and summarized were the materials on the common catfish of the Kuibyshev reservoir, on the clary catfish and pangasius contained in the recirculating aquaculture system of the Department of Water Bioresources and Aquaculture of the Kazan State Power Engineering University since 2016.

\section{Results and discussion}

The only indigenous representative of the catfish (Siluroidea), the European catfish (Silurus glanis L.), is one of the valuable representatives of the ichthyofauna in the Middle Volga region, which has never been significantly represented in catches (Fig. 1). This is one of the largest fish - up to $300 \mathrm{~kg}$ and up to $5 \mathrm{~m}$ long [4], in the conditions of the Kuibyshev reservoir it is most often found from 2 to $10 \mathrm{~kg}$. Catfish are solitary predators confined to pits with snags, near channel sections.

The high rate of weight (Fig. 2) and linear (Fig. 3) growth makes the European catfish an attractive object for aquaculture and sport fishing, and high taste qualities further enhance this. Since European catfish in all regions are found in single specimens [1, 3, 4], the information of fishermen is of interest [9].

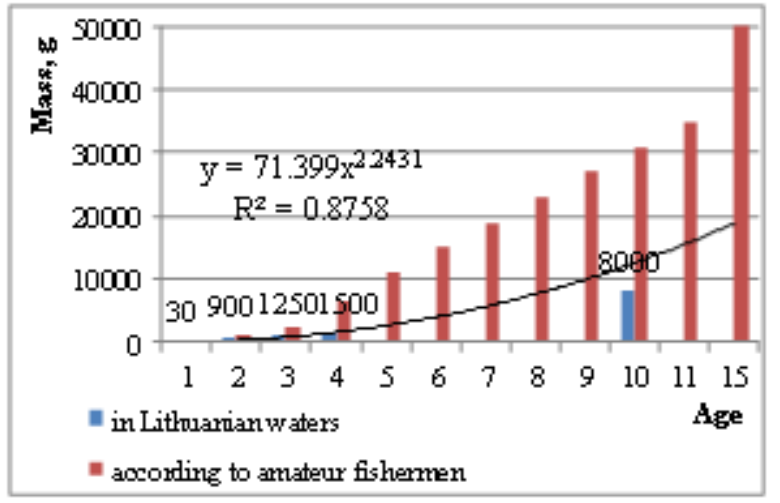

Fig. 2. Weight growth of European catfish in the conditions of Lithuanian water bodies according to [4] and according to data from amateur fishermen [9].

Figures 2 and 3 present in a comparative aspect the data of scientific research [3,4] and the data of amateur fishermen [9]. The materials clearly show the "fishing" tendency to overestimate the real size and age characteristics of catfish.

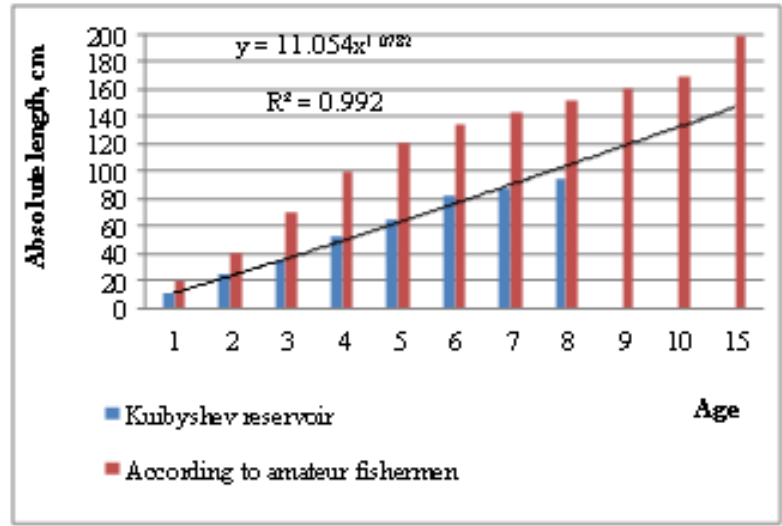

Fig. 3. Linear growth of European catfish in the Kuibyshev reservoir according to [3] and according to data from amateur fishermen [9].

The assessment of the catch of fish by poachers and amateur fishermen in the water bodies of the Republic of Tatarstan showed that catfish is caught on the Kama River (4\%) and the Mesha River (3\%) [7]. The process of natural reproduction of the European catfish in conditions of pasture aquaculture is characterized by a number of features $[4,5]$ : sexual maturity occurs at 4-5 years of age; catfish - phytophils with sticky eggs measuring 2-6 $\mathrm{mm}$ in diameter; couple spawning at a temperature of $18-20 \circ \mathrm{C}$, mass spawning at a temperature of $20-23^{\circ} \mathrm{C}$ in May - June; fertility depends on the age of the female and ranges from 11 to 500 thousand eggs; laying eggs into the nest, which the female builds at a depth of $40-50 \mathrm{~cm}$ out vegetation; the duration of the incubation period is 2.5 - 3 days (60 degree days); the male protects the eggs and aerates the water with the movement of tail.

The development of aquaculture by the 1980s led to the development of biotechnology for the reproduction of European catfish for the production of juveniles and their rearing in pond fish farms [5]. The maximum fish productivity using this technology is $240 \mathrm{~kg} / \mathrm{ha}$.

Taking into account that, according to official statistics, the average fish productivity of the Kuibyshev reservoir is $5 \mathrm{~kg} / \mathrm{ha}$ [6], and considering poaching - 14 $\mathrm{kg} / \mathrm{ha}[6,7]$, European catfish in catches are found in different years at the rate of $0.2-0.5 \%$, then in the structure of fish productivity of the Kuibyshev reservoir they account for about $0.03-0.07 \mathrm{~kg} / \mathrm{ha}$. Further development of biotechnology for the reproduction of European catfish [4] is associated with the methods of taking eggs and sperm from injected producers for further incubation in apparatus. A feature of working with males of the European catfish is the euthanasia of males and removal of testes by a surgical method. The weight of $30 \mathrm{~g}$ is achieved by young of the year over a period of about 145-155 days at a pool keeping under optimal conditions on artificial feed (Fig. 4) [4]. 


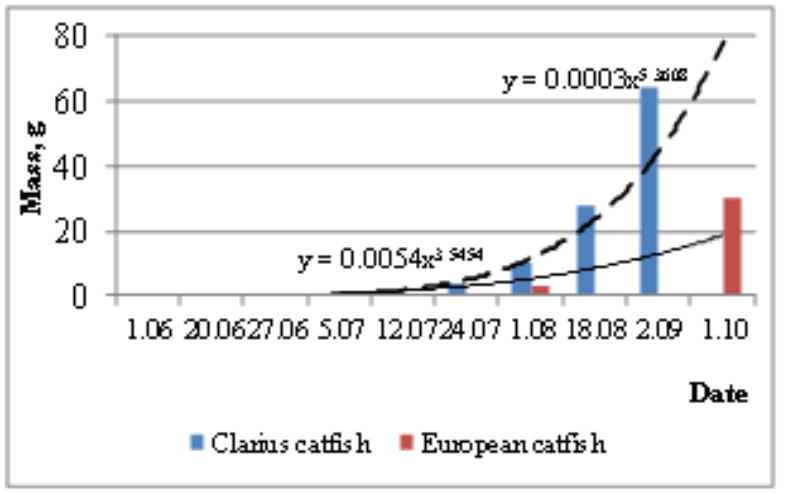

Fig. 4. Weight growth of juvenile European and Clarius catfish in biotechnology of artificial reproduction.

The average daily growth (Fig. 4) of juvenile Clarius catfish was $0.20 \mathrm{~g}$ or $95.24 \%$ of body weight, of European catfish, respectively, $0.44 \mathrm{~g}$ or $14.67 \%$.

An important aspect of juvenile rearing is to prevent cannibalism, which is a characteristic for both juvenile European catfish and Clarius catfish.

The efficiency of fish farming can be increased by intensifying production, for example, by introducing new objects with a rapid growth rate into the culture of cultivation: catfish acclimatizers, are also involved in aquaculture in Russia [5, 10, 11].

In 1972, channel catfish - Ictalurus punctatus Raf, the main objects of commercial fish farming in America and the favorite objects of sport fishing were brought to Russia. Methods of their reproduction were developed: pond, cage and aquarium. Channel catfish were actively used for cultivation in cage farms on warm waters of energy facilities $[10,11]$.

Among the most promising objects of cultivation on warm waters in recirculating aquaculture systems is the African Clarius catfish (Clarias gariepinus), work on the cultivation development of which began in Russia since 1996 [12]. Claria have a high rate of mass accumulation (Fig. 4): from larvae to a marketable weight of $1.2 \mathrm{~kg}$, the growing time is six months in conditions of RAS, in addition, they are resistant to diseases [12].

Whereas the ability to survive in conditions of low oxygen content in Clariidae catfish is associated with the presence of a supragillary organ, in European catfish the skin is covered with mucus and contains cells that can absorb oxygen $[4,5]$, which allows the European catfish to withstand long periods of hypoxia, depending on the water temperature.

An increase in the share of consumption of aquaculture objects in the diet is an objective trend associated with a number of factors, such as an increase in population, a decrease in catches from natural aquatic ecosystems, the need to consume valuable protein products, an orientation towards a healthy lifestyle [17]. Recent data on world aquaculture [17] shows a steady increase in the production of both Clarius catfish and pangasius (Pangasianodon hypophthalmus) (Fig. 5).

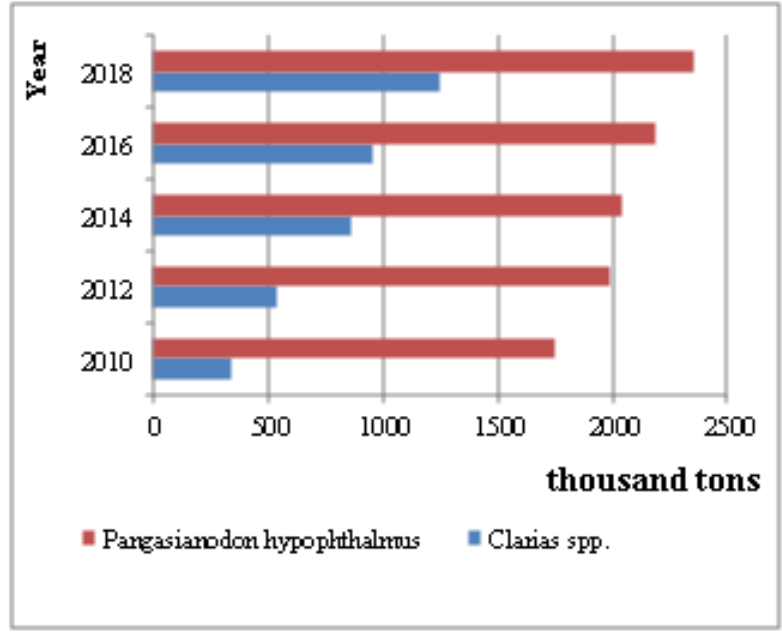

Fig. 5. Catfish produced in world aquaculture in the largest volumes by [17].

For the inclusion of claria in commercial farming production, it is necessary to have an established production of juveniles. In this regard, work was carried out to assess the possibility of obtaining sex products when using surfagon for injection of producers [18].

The experience of reproduction of Clarius catfish was also studied within the framework of the internship of the master student of the Department of Aquatic Bioresources and Aquaculture of the Kazan State Power Engineering University at the University of Rostock (Germany) in the period from 1.10 .19 to 31.11 .19 under the grant of the Government of the Republic of Tatarstan "Algarysh" and the Memorandum on joint activities in the field of aquaculture with the University of Rostock.

The experiments carried out revealed the possibility of pre-spawning maintenance of clary catfish in conditions of low recirculation, the applicability of technological methods of reproduction of Clarius catfish by the factory method. The results revealed the possibility of using surfagon suspension for injection, which is used in our country for injecting sturgeon. In Germany, drugs used for salmonids were applied to inject claria.

If, when obtaining reproductive products, it is possible to obtain eggs from females by the method of decanting and preserving their life, then the need to slaughter males to obtain reproductive products reduces the efficiency of the formation of the broodstock. The method of slaughtering males was used to obtain sperm from the Claria both in our laboratory and in Germany. However, if we watered the caviar dry with milk from the cut testes, then when the eggs were inseminated in a German laboratory, the testes were finely chopped, the caviar was watered not only with milk, but also with water, in which the chopped testes were washed. Sexual products were collected after injection.

The best result was achieved when the producers were stimulated with a suspension of surfagon $-3 \mathrm{mg} / \mathrm{kg}$ of body weight of catfish with the addition of a vegetable additive - raunatin with a sedative effect.

We used females raised in the departments RAS with a mass of 560 to $4000 \mathrm{~g}$; in Germany, the mass of 
females used to obtain eggs varied from 5.6 to $9.8 \mathrm{~kg}$, Vlasov V.A. [19] noted that the first time maturing females of Clary catfish weighed $200 \mathrm{~g}$ with a length of $26 \mathrm{~cm}$. Considering that the working fertility varied from 60 to 100 thousand pcs / $\mathrm{kg}$ [19], the minimum working fertility was 12 thousand.

In our experiments, the average working fertility of female Clarius catfish was 72.8 thousand pcs. (Fig. 6), the minimum is 10.3 thousand pieces in a female weighing $560 \mathrm{~g}$. Fertility of eggs is 70 to $90 \%$. The average weight of one egg is $1.85 \mathrm{mg}$.

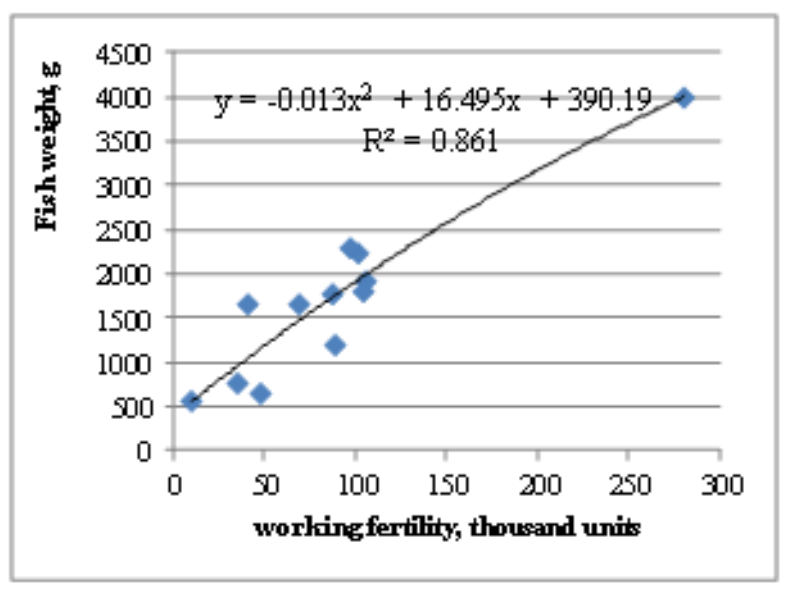

Fig. 6. Working fertility of female Claria depending on body weight.

The dependence of the value of working fertility on the female body weight is described by the equation $\mathrm{y}=$ $-0.013 x^{2}+16.495 x+390.19$

The German company PAL (Abtshagen, Germany) does not use the methods of de-gluing caviar and it is kept at a temperature of $27-28^{\circ} \mathrm{C}$ in aquariums, where aeration and water circulation are provided. One day after fertilization, the embryos in the egg begin to actively rotate and after another 4-6 hours they hatch.

The mass of males participating in reproduction varied from 522 to $1560 \mathrm{~g}$. The average weight of testes was $9.37 \mathrm{~g}$ and varied from 0.82 to $2.09 \%$ of body weight. The mass of empty testes in different males differs much less in percentage of body weight than in full ones. The weight of full testicles depends on the weight of the fish. The equation for the relationship between the mass of a full testis and the mass of a male Clarius catfish $\mathrm{y}=0.061 \mathrm{x}^{2}+1.3113 \mathrm{x}+0.8833$.

The males used for reproduction in Germany had a body weight of $3.5-4 \mathrm{~kg}$, and the amount of obtained seminal fluid varied around $15-20 \mathrm{ml}$. The use of large adult producers is highly preferred by the local organization: sex products from large adult producers are of significantly better quality, larger percentage of body weight and easier to handle.

During incubation in Weiss apparatus at a water temperature of $27{ }^{\circ} \mathrm{C}$, hatching began 20 hours after fertilization of eggs.

The rate of weight growth of juvenile clary catfish (Fig. 4) is higher than that of the European catfish. The combination of the possibility of artificial reproduction, year-round cultivation in warm waters by industrial methods, the ability to withstand high stocking densities and ensure high fish productivity make the Clarius catfish one of the best objects of modern industrial aquaculture.

At the same time, industrial aquaculture methods best meet the conditions for a significant increase in the productivity of aquatic ecosystems, allow fish to be raised using resource-saving and environmentally friendly technologies. This allows us to further expand the range of catfish grown in aquaculture farms. Perspective objects of artificial reproduction are other representatives of catfish - shilba catfish - Siamese pangasius (Pangasius sutchi (Fowler, 1937)) [8], and Pangasius hypophthalmus from the Pangasiidae family, which is called shark catfish. P. Hypophthalmus is comparatively larger and more aggressive, has a status of a threatened species [20].

These species entered the aquaculture of Vietnam and received wide world recognition as promising objects of industrial cage culture. They can be used for cage culture in warm waters of energy facilities. For these purposes, it is necessary to have planting material juvenile pangasius. Biotechnology that developed in Vietnam [20] includes both the use of ponds and pools. For reproduction, individuals weighing about $2 \mathrm{~kg}$ are selected from the broodstock, which includes the first maturing individuals at the age of 3 years and older - up to 10 years. Preparation for artificial reproduction includes the stage of their intensive feeding with industrial or prepared feed supplemented with vitamins and a nutritious liquid - squid liver oil [21].

Hormonal injections are performed with human chorionic gonadotropin (hCG) or gonadotropin-releasing hormone (gonadoliberin), which are administered by $3-4$ injections for females, 1 for males. The injections induce egg maturation and ovulation approximately 8 hours after the last injection [21].

The growth of juvenile pangasius in a plant with a closed water supply is shown in Fig. 7. The average daily increase was $7.2 \%$ of body weight and $48 \%$ in Vietnam.

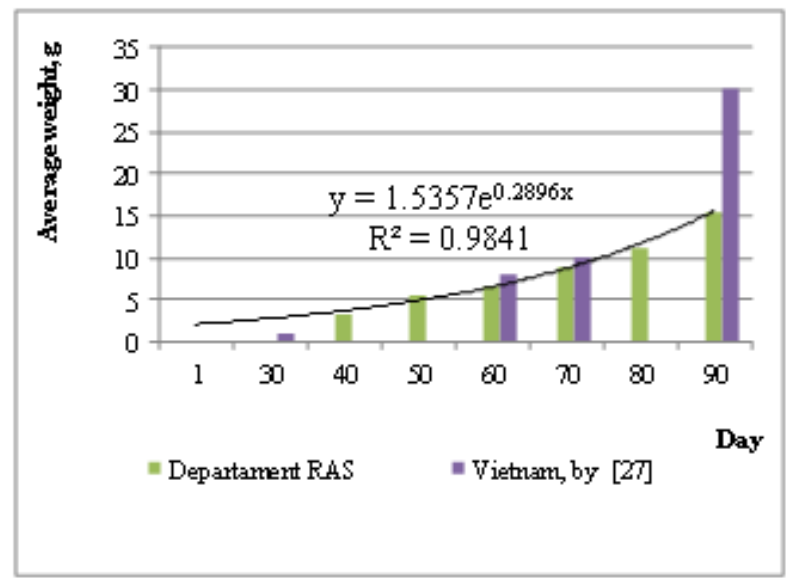

Fig. 7. Weight growth of Pangasius hypophthalmus.

Pangasius can be used for cage culture in warm waters of energy facilities. It is necessary to have planting material that can be obtained by biotechnology 
[20]. For reproduction, individuals weighing about $2 \mathrm{~kg}$ are selected from the broodstock, which includes the first maturing individuals at the age of 3 years and older - up to 10 years.

Scientists in Malaysia and Thailand often use hybridization to take advantage of potential desirable cultural traits in offspring to increase the growth rate of Clarius catfish and pangasius, increase their resistance to diseases, improve resistance to extreme environmental conditions and improve other characteristics [22]. However, despite the possibility of these many advantages, many previously described hybrids have not acquired relevance for aquaculture [23].

\section{Conclusion}

It is possible to increase the efficiency of fish farming by introducing new objects with a fast growth rate into the culture of cultivation: the Clarius catfish. It has a higher weight growth rate than European catfish and pangasius. Comparison of the weight growth rate of juveniles of Clarius catfish, European catfish and Pangasius, size-weight group from 1 to $50 \mathrm{~g}$ showed that the maximum average daily gain was in the Clarius catfish $-95.24 \%$ of body weight, in the European catfish, respectively $14.67 \%$, and in pangasius in the conditions of the RAS department $-7.2 \%$ and $48 \%$ in Vietnam. The use of European catfish, clarias and pangasius in aquaculture makes it possible to expand the list of aquaculture objects in waters with different thermal regimes.

The conducted experiments revealed the possibility of pre-spawning keeping of Clarius catfish in conditions of low recirculation, the applicability of technological methods of reproduction of Clarius catfish by the factory method. The results revealed the possibility of using surfagon suspension for injection, which is used in our country for injecting sturgeon fish. The best result was achieved when the producers were stimulated with a suspension of surfagon - $3 \mathrm{mg} / \mathrm{kg}$ of catfish body weight with the addition of a plant-based additive - raunatin with calming or sedative effect.

The further development of biotechnology for the reproduction of European catfish is associated with the methods of taking eggs and semen from injected producers for further incubation in apparatus.

It is necessary to further refine the technology of reproduction and raising of catfish on the waters of energy facilities with different temperature regimes.

It is possible to increase the production of European catfish in the region of the Middle Volga region due to biotechnology of artificial reproduction and pasture aquaculture on the basis of water reservoirs with natural temperature regime. On the warm waters of energy facilities, highly industrial aquaculture production of Clarius catfish can be organized, which have the highest weight growth rate and allow obtaining the highest fish productivity per unit of water volume.

\section{References}

1. P.A. Dryagin, Fish of inland waters of the USSR: Handbook of small-water fisheries (M.-L.: State publishing house OGIZ, 20-51, 1934)

2. N.I. Kozhin, Basic principles of sustainable lake fisheries: Small water fisheries handbook (M.-L.: State publishing house OGIZ, 52-79, 1934)

3. S.S. Gainiev, Fishery importance and some aspects of catfish biology of the Kuibyshev reservoir, Biology and ecology of fish in the Kuibyshev reservoir: Scholarly notes (Ulyanovsk: Privolzhsk book publishing house, 59-68, 1966)

4. E.I. Khrustalev, V.V. Bruchanov, Biotechnical and production potential of pasture aquaculture in transboundary water bodies of Russia and Lithuania (Kaliningrad: publishing house "IP Mishutkina I.V.", 198, 2009) ISBN: 978-598787-034-1

5. V.I. Kozlov, L.S. Abramovich, Fish farmer's guide (M.: Rosselkhozizdat, 220, 1980)

6. M.L. Kalaida, History and prospects for the development of fish industry in Tatarstan (Kazan: Publishing house "Matbugat Yorty", 96, 2001)

7. M.L. Kalaida, The need to take into account amateur and poaching fishing in the aquaculture of reservoirs, Aquaculture at the beginning of the XXI century: origins, state, development strategy, Materials of the International Scientific and Practical Conference, Rybnoe village, Moscow, Publishing house VNIRO, 88-91 (3-6 September 2002)

8. A. Islam, M.L. Kalaida, Shill pangasia catfish Pangasius sutchi (Fowler, 1937) - a promising object of aquaculture, Biodiversity and biological resources of the Middle Volga region and adjacent territories, Collection of materials dedicated to the 125th anniversary of Kazan State Pedagogical University, Kazan, 150-151 (2002)

9. Catfish weight and age [Electronic resource] Available at: https://www.gribalka.com.ua/Stati/Lovlyasoma/Som-ves-i-vozrast.html (accessed: 10.01.2021)

10. V.I. Vinogradov, L.V. Erokhina, V.F. Krivtsov, L.V. Kolmykov, Breeding and rearing channel catfish (guidelines) (M: VNIIPRKH, 46, 1982)

11. Fish-biological standards of fish growing on warm waste waters of thermal power plants and nuclear power plants (M: VNIIPRKH, 34, 1985)

12. V.A. Vlasov, Results of rearing African catfish under various conditions of feeding and housing, News of TSKHA, 3, 136-146 (2009)

13. S.B. Podushka, Clary catfish and its use in fish farming, State and prospects for the development of fish farming in the arid zone (Rostov n /D., 7174, 2006) 
14. Background information on the development and support of aquaculture (fish farming) in the Russian Federation (M.: $\quad$ FSBSI "Rosinformagrotech", 64, 2017)

15. M.L. Kalaida, The current state and tasks of aquaculture development in the Republic of Tatarstan, The state and development of aquaculture in the Russian Federation in the light of import substitution and ensuring the country's food security: materials of the national scientific and practical conference, Saratov, Saratov: p. h. "Scientific book", 38-45 (4-5 October 2016)

16. V.A. Vlasov, Cultivation of Clarius catfish (Clarias gariepinus Burchell) under different conditions of housing and feeding, Scientific foundations of agricultural fish farming: state and development prospects, Collection of scientific papers of the VNII of Irrigation Fish Farming, 168-179 (2010)

17. Food and Agriculture Organization of the United Nations [Electronic resource], The State of World Fisheries and Aquaculture (2018) Available at: http://aquacultura.org/upload/files/pdf/library/fao (accessed: 20.02.2020)

18. M.L. Kalaida, E.S. Piganov, A.A. Kalaida, M.F. Khamitova, Clarias gariepinus catfish for artificial reproduction, Status and development of aquaculture in the Russian Federation: V National Scientific and Practical Conference, under ed. A.A. Vasilieva, Saratov GAU, Saratov: Amirit, 108-112 (22-23 October 2020)

19. Recommendations for the reproduction and cultivation of Clarius catfish using installations with a closed cycle of water supply: instructional method (M.: FGNU "Rosinformagrotech", 48, 2010) ISBN: 978-5-7367-0757-7

20. Strategic alliance for sustainable aquaculture Pangasius Farming Practices In Vietnam, A study in view of sustainability issues, A GTZ, Binca PPP program, Designed by Gregoire Poisson and collaborators (2004)

21. J. Subagia, J. Slembrouck, L.T. Hung, et all, Larval rearing of an Asian catfish Pangasius hypophthalmus (Siluroidei, Pangasiidae): Analysis of precocious mortality and proposition of appropriate treatments, Aquatic Living Resources, 12 (1999)

22. A. Kiriyakit, W.G. Gallardo, A.N. Bart, Successful hybridization of groupers (Epinephelus coioides $\mathrm{x}$ Epinephelus lanceolatus) using cryopreserved sperm, Aquaculture, 320, 106-112 (2011)

23. S.O. Olufeagba, V.T. Okomoda, Cannibalism and performance evaluation of hybrids between Clarias batrachus and Clarias gariepinus, Croatian J. Fish., 74, 124-129 (2016) 